\title{
Service Development for Progression of Dance
}

\author{
Anastasiya Yurchyshyna \\ Fondation CINTCOM, Chemin de Champ-Claude 10, 1214, Vernier, Switzerland
}

\begin{abstract}
This research explores transdisciplinary knowledge, skills, motivations, values, deep expectations of all members of Society interested in Dance, in order to integrate established knowledge on development of services and information systems with the exploration of the progression of Dance in an open environment of digital innovation, initiatives management, social networking, crowdsourcing and public engagement. This leads to identifying the innovative ideas for resilient and sustainable progression of Dance in the situation of pandemic and to developing a myriad of services assisting this progression. This research is oriented towards service development, by identifying innovative ideas aiming at the progression of Dance in the situation of pandemic, concretising them as information common goods and organising them as informational commons, in order to actionalise them as contributory services. To support the development of services in a sustainable and responsible way, it suggests to develop a protected place adapted to co-construction of information services, Tiers-Lieux for Services (TLS), which allows identifying added value of all initiatives, so that responsible and interested persons could all actively participate in actionalising the created added value for the development of dance-related services.
\end{abstract}

\section{Introduction}

Our Society exists in the time when the Digital comes into all spheres of human activities, often reconsiders their reasons of being, redefines the principles of their functioning, leads to major transformations in exchanges between people, institutions, businesses and governments. This is a continuous process since new situations consistently appear. They conduce new demands on people's activities, change their practices, require new skills and know-hows, provoke additional obstacles, lead to unhackneyed uncertainties: e.g. education with social distancing, virtual tourism, etc. One of the most significant features of this process is its transdisciplinarity, when knowledge and skills from multiple domains enrich and empower different spheres of human activities and enlarge the opportunities for the progression of Society. The "success" of Society can now be measured not against a theoretically determined optimum, i.e. not by its development, but by a different concept that would allow considering Society as a living being, which constantly changes in a non-predefined way, in the conditions of the incomplete knowledge and according to the next best alternatives. This is the concept of the progression of Society [1]. The progression of Society outperforms the notion of the development of Society, which is concretised by already established pre-defined objectives. The progression of Society 
outperforms the notion of the evolution of Society, which is defined by a gradual directional change leading to a more complex form. Both these notions would place Society as it is today to pre-define the way it will transform to become "better" or "more developed". They do not take into consideration the possible extension of different spheres of Society, which might even not exist before. In contrast, progression allows integrating the continued expansion of human societies, as it envisages Society as a being, constantly changing and transforming. Throughout its progression, it becomes possible to evaluate what exactly is right and sustainable in transformations induced by technologies and the Digital, and to respond accordingly with new activities and undertakings. The concept of the progression is in the heart of the exploration of Society. It tackles the situations and investigates the opportunities they might induce, which encourages all members of Society to actively participate in its activities, come with their initiatives, co-create value, and all this in a responsible way, according to the conditions needed to place the digitalisation at the service of sustainable progression.

The world of Dance has been dramatically influenced by the pandemic of coronavirus and the related consequences. Theatres are closed, practicing and performance places for dancers are limited and/or restricted, physical, emotional and financial difficulties are extensive.

Public space in Dance has been extended to homes and digital spaces. New forms of training and performing practices appear. Alternative approaches for financing are being searched for. It is a real challenge for dancers to be resilient and continue creating and performing. It is a most urgent question for the domain to remain sustainable and find renewable long-lasting ways for its progression.

In this context, it becomes essential to explore transdisciplinary knowledge, skills, motivations, values, deep expectations of all the members of Society interested in Dance, in order to identify the innovative ideas for resilient and sustainable progression of Dance and to develop a myriad of services assisting this progression. This includes, but is not limited to, the following vast and complex topics:

- How should Dance progress today inside Society, to ensure it is done in a sustainable and continuous way?

- Which new business models, new forms of governance and new ways for public engagement emerge nowadays?

- Which new professions related to Dance are created? How can digital technologies assist corresponding social transformations?

- How to bring out the value (both cultural and economic) of new digital developments to ensure the continuity of dance activities?

- How can dancers remain resilient, by exercising their activities and by being able to respond to unpredicted challenges? How can they re-evaluate their position regarding progression and explore new knowledge and skills?

- How to explore the own disciplines of various interested persons to use their knowledge efficiently for dance-related services?

- What is the influence of extended digital space for performances and event management?

- How to formalise initiatives regarding the progression of Dance, in order to create dance-related information common goods and develop services?

The above topics show the aim of this research, whose contribution focuses on the development of transdisciplinary services aiming at the progression of Dance, and such services can be concretised to tackle any aspect of such a progression. 
It is important to underline that, as it is in the case of the progression, which can not be summarised by its pre-defined objectives, this exploratory research can not be evaluated, according to the pre-defined expected results. It is a study of opportunities, an analysis of weak signals [2] resulting from the influence of pandemic on Society, first indicators of breakthrough changes and/or emerging issues that may become significant in future. It is thus the exploration itself, not its correspondence to expected results and achieved (or not) initial objectives, which would specify the created added value of this research. This paper does not aim at proposing solutions to problems. The exploratory nature of this research tackles new situations and challenges brought by the pandemic to Dance Society, some not yet even identified. Therefore, it does not aim to address well-understood problems and does not search to offer corresponding solutions to resolve them. This upstream research explores new situations and identifies issues at stake, it analyses primary responses of Dance Society to new, never before known situations, it suggests an approach aiming at identifying innovative ideas, which might or might not contribute to the progression of Dance Society, and, when possible, at making them actionable [3] with the means of information services.

The paper is structured as follows. Section 2 discusses the current tendencies in the progression of our Society. Section 3 outlines the new challenges brought up by the pandemic and describes the first answers to the pandemic in the world of Dance. Section 4 introduces the exploratory approach for identifying innovative ideas aiming at the progression of Dance in the situation of pandemic and concretising them as services. In conclusion, some perspectives for further research are outlined.

\section{Society: what we face today}

This section describes the main tendencies of our Society, which help its progression and thus should be taken into consideration in service development.

\subsection{Society and the Digital}

The Digital has come into all the spheres of our Society. Indeed, the process of digitalisation is not a simple automation of business and societal processes, but a full integration of digital technologies into all areas of human activities. They do not only change the way these processes function, how enterprises are organised and how the value is delivered. Digital technologies become a moving force in creating new activities, exploring new processes and assisting Society in discovering new situations and answering new challenges.

\subsection{Role of Service Science: everything is a service}

The role of services nowadays is truly fundamental. Services come from multiple independent innovations and contribute significantly to the dynamics of contemporary societies. Most often, they owe their emergence to intense, interdisciplinary, inter-institutional, and often international collaboration. In particular, such collaboration must concretely, at the service level, consider the relationships between the private and the public, including making services compliant to the regulatory framework, consequently precipitating profound societal changes.

A service in Service Science $[4,5,6]$ is characterised by the value that this service must add. Its aim is not simply to make more efficient business processes, as in the case of information systems. It must add value to the business by creating situations, from which 
value may emerge. Services are so fundamentally informational, where "information" can mean data, information or even knowledge to persons according to their duties and responsibilities.

Society can thus be viewed as progressing thanks to services, which address new situations, help to actionalise added value of numerous innovations, concretise this value proposition for activities of Society [1] and enable their implementation.

\subsection{Balance between market economy and economy of contribution}

Another important aspect of our Society is the co-existence and interdependence of two types of economies: the traditional market economy and the economy of contribution.

It is essential to note that the economy of contribution [7] does not aim at putting into question the traditional market economy, but surpasses its vision by taking into account the new phenomena, such as technological progress, networking, and social media, allowing more possibilities to create and share value.

The economy of contribution is characterised by the following characteristics [7]: (i) no separation between economic actors as producers and consumers; now all actors are seen as contributors (co-creators) who participate in chosen activities for creation of (material and/or) social value; (ii) the value produced by contributors is not totally monetisable, it is a "positive externality"; (iii) it is both an economy of existence (as the production of "savoir vivre") as it is an economy of subsistence; (iv) it does not exclude alternative means of production and exchange, but combines with them.

Thanks to digital technologies, heterogeneous actors are encouraged to take part in collaborative multicultural and inter-generational environments [8] in different service-oriented projects [9] fostering value co-creation. These actors thus become active participants in suggesting innovative ideas, discussing them, concretising them and enabling them as services. In this way, they all enrich collective creative practices and new value-creating mechanisms, whilst digital technologies support creating and disseminating information and knowledge.

\subsection{Interdisciplinarity}

Complex, multicultural and international, our Society is also characterised by the interdisciplinarity of its processes. Long ago its processes stopped being narrowed to one (or a limited number of) major domain(s), but truly benefited from a variety of different disciplines. Both Society, in general, and Dance, in particular, base their progression on the success in collaboration with other domains, enrich themselves with innovative ideas from persons outside their domains and strengthen their knowledge bases with added value coming from various interdisciplinary activities.

For our servitised Society, in the context of the economy of contribution, the following interdisciplinary interchanges become particularly significant for Dance: (i) the role of media in Dance as a performing art; (ii) communication and growth of dance community thanks to social media; (iii) popularisation of professional routines and creating new professions related to Dance; (iv) using Dance as a language in the architecture of medical and social information; (v) application dance techniques in academics aiming to increase memory, order, and sequencing skills; (vi) dance psychology for leadership and management allowing improving creativity, communication, critical thinking and collaboration. 
All the above lead to exploring various domains, taking into consideration ideas coming from heterogeneous actors, benefiting from added value of collaboration and supporting the progression of Society, in general, and Dance, in particular.

\section{First answers to the pandemic in the World of Dance}

The world of Dance is by its nature creative and imaginative. This is a performing art, often based on a narrative and widely supported by different means of artefacts to explore the story. It uses allegories, offers slightest hints, encourages spectators' imagination, seeks for alternative ways of expression. No wonder, it immediately - non-trivially and creatively responded to challenges brought by the pandemic.

Despite being dramatically influenced by the pandemic of coronavirus and the related consequences, the world of Dance has nevertheless immediately started to seek alternative approaches: public space in dance has been extended to homes and digital space, new forms of training and performing practices appear, new forms of financing and events management are being searched for.

It has resulted with the following effects (cf. Table 1), which are categorised and described thanks to review of literature and online sources, interviews with professionals in Dance, as well as author's observation, personal involvement in new practices and active participation in the Dance community.

Table 1. First responses to the pandemic in the world of Dance.

\begin{tabular}{|l|l|}
\hline Effect & Description \\
\hline Strength & of Dance community thanks to mutual support \\
\hline & by openness and willingness to embrace technology \\
\hline Extension & by improving of standards of hygiene practices \\
\hline & to homes and digital places \\
\hline & of forms of training \\
\hline Sharing knowledge & of forms of performances \\
\hline New & by opening professional classes for public \\
\hline & forms of financing classes \\
\hline & $\begin{array}{l}\text { forms of financing theatres, companies and events } \\
\text { management }\end{array}$ \\
\hline Creating & activities and professions \\
\hline
\end{tabular}

- community is getting stronger and bigger

The Dance community is originally very supportive, due to the nature of this art: it is a collaborative activity where the success is based on the best coordination and performance of each member. The Dance community is very inter-disciplinary and international. During the pandemic, the community has responded in the most prominent way by supporting each 
other thanks to digital technologies. The leading dancers and companies (e.g. Tiler Peck, principal dancer with NYC ballet, Vladimir Malakhov, former artistic director of Staatsballett Berlin) have been organising online classes and talks, webinars and cooking classes, by inviting not only professionals of dance, but all interested members of Society

- openness and willingness to embrace technology

Dancers are open to new creative ideas, tools and technologies. The solutions the Digital brings, which initially aim at approaching "normal" routines, have been integrated by dancers as extended opportunities and enlarged their daily practices (e.g. shared learning in virtual spaces).

- improving the standards of studios and hygiene practices

With the increased risk of contamination, dance companies and schools follow and respect the suggested recommendations on indoor activities: e.g. social distancing, wearing masks, disinfection, etc. Moreover, some of them implement advanced technologies, in order to ensure safety of dancers and spectators. For example, Yen Han Ballet Productions [10] has integrated UVC air cleaners in all their company and school locations. Another approach is to modify studios for making dance-related activities safe, as was done by Toronto's LMNTS Studio [11] which has set up outdoor frameless domes for COVID-safe yoga practices.

- public space of dance is extended to homes and digital spaces.

This relates to both training (e.g. organising a mini ballet studio in the kitchen with basic arrangements like a barre or kitchen top and removable marley floor) and performance (e.g. streaming concerts of dancers performing simultaneously the same choreography but from different locations).

- expanding forms of training

By extending the public space of Dance into digital spaces, new forms of training emerged. For example, live classes on social media (e.g. instagram) with Tiler Peck with around 2000 participants from all over the world. Another example is live classes thanks to video conferencing (e.g. zoom) for dance professionals with Dance Live Europe initiative [12] where all participants see each other and can communicate in real time.

- extending forms of performances

This includes streaming previous shows (e.g. San Francisco ballet, Dutch National Opera, Opéra de Paris, etc.), streaming documentaries (e.g. Béjart Ballet Lausanne), streaming performances with no public (e.g. Royal Opera House), performances with orchestra, which is located in a different location (e.g. Opernhaus Zürich), performances with a reduced orchestra (e.g. English National Ballet), performances en plein air (e.g. Staatsoper Hannover), choreographies in digital spaces, etc.

- opening professional classes for public and disseminating knowledge

The example is Tamara Rojo, the artistic director and a principal dancer with the English National Ballet, who was giving daily company classes available to everyone. In such a way, the classes and the related knowledge are becoming a common good, as several dancers continue including online training into their daily routine after the lockdown measures eased. This also has led to creating new practices.

- new forms of financing classes: classical, donation-based, investment in promotion, solidarity movement, supported by advertisement

With traditional forms of paying per class both in offline and online modes, new forms are being developed. The vast majority of online classes are donation-based (e.g. Dance Live Europe), free (granted by dance schools during their closure, e.g. Tanzwerk101, Zurich), free (offered as a part of the promotion of the company or in a "solidarity movement", e.g. Analia Domizzi, a choreographer and the artistic director of Teatro Colón, 
Buenos Aires) or supported by advertisement (e.g. collaboration between Maria Khoreva, 1st soloist with Mariinsky, and Nike and Bloch). These new forms of financing classes are not yet formalised enough to be concretised as innovative business models, however, they can serve as an initial basis for developing a new model applicable in the situation of pandemic.

- new forms of financing theatres, companies and events management

Traditionally, theatres, dance companies, freelance dancers rely on governmental support, different funds, donations, income from performances, some are organised as charities, etc. All of the above have become highly problematic in the situation of the crisis and severe economic consequences resulting in the pandemic of coronavirus. A lot of freelance dancers, small companies, but also major successful companies can not survive and cease to exist. For example, a highly successful Cirque du Soleil, Montreal, has filed for bankruptcy protection. New forms of financial support are now required. Some theatres offer online concerts at a small fee, some re-evaluate their policy regarding commercial dance, some look for new configurations of spectators places to satisfy the requirements of distancing and the related price policies, some create emergency funds.

- new activities and new professions

Previously unheard of, new activities and professions are already sprouting. New skills are now highly sought after: (i) coaching a dancer in real time with the help of social media (e.g. instagram); (ii) coordinating and working on choreography by using video conferencing (e.g zoom); (iii) developing techniques for alternative training for a dancer to master grand allegro in limited space; (iv) providing leading dancers an alternative opportunity to excel without a possibility to practice in a studio and/or on a stage; (v) researching physiological and psychological impacts of training in medical masks on a dancer's health; to mention but a few.

- creating a resilient and sustainable dance ecosystem, which is not repairing the previous one with a few elements of "a new normal", but exploring its progression towards resilient and sustainable place for Dance inside Society

These first answers are weak, yet significant signals, which have already witnessed that a lot of members of Society are interested and actively collaborate in suggesting innovative ideas, finding the way of implementing them, as well as co-designing new facets of dance-related activities.

As far as the author's knowledge, whilst being on the early stage of the pandemic, the formal research regarding Dance in the situation of pandemic can not yet boast an extensive academic material. At this stage, all types of research methods - surveys, observation, primary and secondary data collection and analysis, experimental research, case studies, etc. - are of great importance. There is an undeniable interest and an immediate call for complex research in the academic community, which have not yet had a possibility to present their research. For example, for the domain of Dance, one of the first possibilities is offered by the Journal on Research on Dance Education, which is currently preparing a special issue on the Innovations in Arts Practice devoted to the impacts of the global pandemic on Dance Education [13]. This correlates with the upstream character of this research, when Dance Society is still at an early stage of a study of opportunities and tries to identify and explore innovative ideas and first answers helping the progression of Dance in the situation of pandemic.

\section{Exploratory approach assisting progression of Dance: from ideas to services}


The contributive value of the exploratory approach relies on ensuring that the progression of Society is resilient and sustainable, on integrating transdisciplinary knowledge and skills of all interested persons, on developing information common goods with added value and on enabling them as (myriad of) contributory services. This also enlarges the opportunities of the market economy thanks to the economy of contribution by virtue of the added value it provides.

The main stages of the approach are as follows:

1. to identify and concretise initiatives regarding the progression of Dance;

2. to define the principles of working together;

3. to create instruments, which support enabling dance-related initiatives as information services.

\subsection{Towards identifying and concretising initiatives regarding the progression of Dance}

As discussed in 3, a lot of ideas and initiatives have appeared, some of them have already proven to be successful and innovative with added value contributing to the progression. This research of possibilities shows that despite a large number of these initiatives, they still remain comparatively local, so it is the intention of this research to study them and bring them to a more generic level.

In order to identify and concretise initiatives related to the progression of Dance, the following steps are required:

1. to promote an open call for initiatives around the progression of Dance (or some of its components) for all persons with interest, talent and dedication;

2. to explore and consolidate all previous innovations and first answers regarding the situation of pandemic;

3. to enrich them with new ideas and concretise the initiatives accordingly;

4. to define added value of proposed initiatives;

5. to institutionalise them in public or private domains.

A lot of initiatives have already proved their consistency as first answers to the situation of pandemic. They can be grouped under the following categories: (i) space for training; (ii) space for performances; (iii) economical aspects of Dance in pandemic; (iv) community and social innovations; (v) classes and coaching; (vi) sustainable and resilient dance ecosystem.

\subsubsection{Space for training}

Traditional training spaces, i.e. dance studios of various types, are not available during lockdowns and closures, so dancers are obliged to find an alternative for their everyday (often lasting for several hours) training. There have been several initiatives that have been commonly accepted:

- spaces for training are extended to homes, and houses are being (partially) re-arranged for dance practices;

- dancers explore the outdoors, with particular attention to natural surfaces;

- spaces for training are shifted to digital places, which provide extended opportunities and enlarged daily practices (e.g. shared learning in virtual spaces);

- dancers find an alternative organisation of space for dance and brainstorm on using additional props and equipment (e.g. cans of tinned food for practising port de bras in The Swan Lake); 
- alternative spaces for auditions (e.g. home recordings) are accepted by academic dance institutions. They also have their benefits: e.g. less psychological pressure in a competitive environment;

- ballet schools use alternative spaces for exams (e.g. students of Academie Princesse Grace de Monaco had their final exam of the year 2019/ 2020 in an empty garage).

\subsubsection{Space for performances}

Analogically to spaces for training, first initiatives to extend spaces for performances have also proven to work well. They are as follows:

- performances places are extended to homes (e.g. Dance Live Initiative real time performance in May 2020, Nederlands Dans Theater live stream "Stay home and keep on dancing");

- stages go outdoors (e.g. outdoors village-located choreography with Bolshoi dancers, Hannover Staatsoper performance in a public garden staged in a way that the garden becomes a part of stage settings);

- virtual shows are becoming more common: streaming previous performances or real-time shows with no spectators;

- theatres are reorganised: seating plan and orchestra arrangements are modified to make it safe for spectators and artists.

\subsubsection{Some economic aspects of Dance in pandemic}

Challenges brought by the pandemic impel the Dance community to reconsider traditional models.

For example, it is not sufficient to apply the market model of real-time presence dance classes in an online environment. From one side, both dancers and teachers can not fully exercise their activities. Even if digitalisation of studio-based classes provides some support, they still remain rather limited, in comparison to usual classes. Consequently, the added value (and thus a monetised value) of online classes decreases.

In this context, it is remarkable that an open model of free classes has immediately gained its place in the world of Dance. Indeed, almost immediately after the first lockdown was imposed, numerous dancers from all around the world came with an initiative to provide free (or voluntary donation-based) classes for all interested persons. This can be explained by a shared spirit of solidarity, by the necessity to keep one's own shape, by the open source vision in creating and disseminating art. From a different side, such free classes provide a solid base for added value, which can be furthermore monetised in promoting a dancer or a dance school, in possible future advertising contracts, performances, etc.

Initially suggested only as a response to the challenges of the pandemic, online and social media classes have quickly become a complimentary tool for traditional studio-based presence classes. This led dance schools and freelance teachers to enrich their business models by finding an appropriate balance between private and public teaching, studio-based presence classes and online coaching (especially in the case of significant geographical distances).

An analogical situation can be witnessed regarding performances and shows. Theatres and companies find themselves in front of the dilemma of balancing between a traditional market model for organising events and opening free (or reduced price) access to their productions. As it is in the case of classes, the added value of free access to performances 
and shows has long-term advantages in terms of promotion, possibilities for donations, future collaborations, etc.

It is also the time for innovative ideas on new forms of financing for art. Governmental support, organising theatres as charities, sponsoring, income from events are not sufficient any longer. New donation-based models, trust funds, shift to streaming performances on TV and income from it are likely to lead to innovative ideas regarding business models for financing performances.

This is particularly important in the context of reorganising theatres, which are now required to have a restricted number of spectators, suffer from travel restrictions and quarantine requirements, face lost income from becoming more probable last-minute cancellations, etc.

All these new aspects have a significant impact on the economic side of Dance during and after the pandemic and should be considered in developing new business models.

\subsubsection{Community and societal innovations}

The pandemic also triggered an unprecedented multitude of community and social innovations in Dance Society. These innovations are grouped around the following key topics:

- community growth based on mutual support, collaboration and value co-creation;

- application of digital technologies for dance-related online activities and new professions related to them (e.g. online coaching);

- $\quad$ societal shift via popularisation of Dance in non-professional environments;

- creating additional interdisciplinary dance-related activities and taking advantage of their added value: e.g. dance-focused webinars, masterclasses on injury prevention and recovery techniques in the situation of lockdown and post-pandemic.

Whilst first community and societal innovations in Dance sprang spontaneously as immediate answers to the situation brought by the pandemic, they served as indicators for further exploration and creation of added value for the development of services supporting the progression in Dance.

\subsubsection{Innovations in classes and coaching}

Initial innovative ideas in providing an opportunity for classes (in the broad sense: e.g. academic classes, workshops, intensive seasonal training, auditions, coach sessions, etc.) in the situation brought by the pandemic created the basis for the new model, which is based on the combination of the following techniques:

- online one-to-one with feedback (for example, with the help of web conferencing tools, like zoom or skype, and social media, like instagram);

- online one-to-many with feedback (the most used tool in the Dance community today is zoom);

- online one-to-one without feedback (this technique has low added value and is not widely spread);

- online one-to-many without feedback (this technique is typical in the cases when highly ranked dancers share their own classes and rehearsals. It is not a class in its traditional meaning, rather a possibility to access "know-how" aspects of dance routine via "learning by doing" actionable approach. In this category, the most used tool in the dance community today is also instagram); 
- economical aspects of new models: first steps are outlined in 4.1.3, which are now practically implemented and tested during the second (for most countries) wave of the pandemic;

- at the early stage of the pandemic, innovative ideas regarding both alternative spacing and alternative exercising still mainly remain the concern of teachers and coaches who have a broader knowledge of dance activities. However, this also opens a wide possibility for businesses providing dance-related products: dance shoes for alternative surfacing (e.g. parquet or laminate floors), ultra-light removable dance equipment (e.g. ballet barres for home usage), etc.

\subsubsection{Sustainable and resilient dance ecosystem}

As discussed in 3 , by its nature, the world of dance is creative and imaginative. This is one of the reasons why it has a higher degree of resilience, in comparison to other domains.

Resilience is generally known as the capability of systems and individuals to cope with significant adversity or risk [14]. First answers to the pandemic have demonstrated how quickly different members of the Dance community responded to new challenges. This resulted in: (i) emergence of new activities: e.g. choreographing and rehearsing via video conferencing; (ii) changing market segmentation by dance-related businesses, identifying existentially increasing "value-grab" opportunities: e.g. ballet barres and removable marley floors for home usage; (iii) requirements for new services: e.g. musical support for classes through zoom, which is technologically demanding and non-trivial; (iv) high demand on experts in other professions: e.g. professional dance photography and video, to mention but a few.

All the above shows a high degree of sustainability and resilience of the dance ecosystem, which is based on digitalised, contributory-driven Dance Society. Practically, it can be illustrated by the example of Prix de Lausanne 2021 [15], probably one of the most known and acclaimed ballet competitions in the world, which not only dramatically reorganised its format to a digital-based online-only event, but also attracted the largest number of participants during 49 years of its existence.

Since Society is still undergoing the pandemic, it is too early to declare the formation of a new model of the dance ecosystem. However, Dance Society is fully aware of the importance of this matter and is actively contributing to formalising such a model, for instance through online conferences oriented towards restructuring the dance ecosystem [16].

\subsection{Towards defining the principles of working together}

In order to collaboratively work on innovative ideas for developing corresponding services for the progression of Dance, it is crucial to define the principles of working together, which should be shared by all interested persons.

First, it is essential to make sure all actors share the intention to explore a resilient and sustainable Dance Society.

Second, it is important that all actors are oriented to the same actionable sequel, i.e. not only identify a promising innovative idea, but have it concretised and implemented as a service with added value.

Third salient point is to analyse a contributory aspect of an innovative idea, to guarantee its responsible, democratic and inclusive characteristics [1]. 
Finally, with the help of Service Science specialists [17], this innovative idea should be concretised and valorised, in order to be implemented as a (myriad of) service(s).

\subsubsection{Sharing the intention to explore resilient and sustainable Dance Society}

All persons who are interested in the progression of Dance, intend to take part in and contribute to the success of resilient and sustainable Dance Society.

They can come from various domains:

- dancers: e.g. member of a company, freelance dancer, dance captain, aerial artist, commercial flash mob dancer, etc.

- non-dancers: e.g. spectators, physiotherapists, high school teachers, builders, dancewear producers, etc.

- both of the above: e.g. a former principal of a national company can pursue her/his further career as its artistic director, or work in arts administration, or excel as a dance photographer, etc.

Despite such heterogeneity, it is important to ensure that all interested persons all share the intention to explore a resilient and sustainable Dance Society. Since interested persons are coming from different professional backgrounds, it might be required to formally define and agree on the semantics of resilience and sustainability in the context of Dance.

\subsubsection{Objective-oriented innovation process}

The solidity of the exploration process on the progression of Dance is based on its objective-oriented character. Indeed, after having identified a promising innovative idea, it is crucial to collaboratively discuss it, delve deeply into it, analyse its expected added value and feasibility, and outline an approach to implement it as a service.

\subsubsection{Contributory aspects of the initiatives}

Innovative ideas suggested by persons interested in the progression of Dance define initiatives, which should be contributory. This means that they should be: democratic, responsible and inclusive.

A democratic initiative is not a fixed creation. To improve its quality, there should be a possibility to criticise and modify it, its intention and meaning should be pellucid to all interested persons, independently of their professional domains, and all of them have equal rights and opportunities to collaborate on its concretisation.

The progression of Society is based on responsible initiatives, which are resilient to changes in the environment and sustainable in the context of guaranteeing the coherent growth and success of Society.

The inclusive aspect of an initiative is salient. Not only all interested persons should have equal rights and opportunities to contribute to identification, exploration and concretisation of initiatives, but it is the heterogeneity of their professional domains, knowledge bases, practices and cultural backgrounds that enrich the initiative and increase its added value.

\subsubsection{Role of specialists in Service Science in valorising dance-related initiatives}

Whilst dance-oriented initiatives are suggested, discussed and improved by all interested persons independently of their domains, the process of concretisation of their added value, 
actionalisation for service design and implementation as a (myriad of) service(s) is possible thanks to Service Science specialists.

When, as a result of discussions and explorations, the interested persons suggest and agree on an initiative, it is concretised as an information common good, with the help of Service Science specialists. Based on the concept of common goods [18], an initiative is formalised as an information common good, which basic resource is data, information and knowledge [19, 20]. Furthermore, information common goods are organised as informational commons $[20,21]$ that makes them more resilient and efficient. By enabling informational commons, Service Science specialists concretise the added value of the initiative, and consequently of a corresponding service, and actionalise it for service development.

\subsection{Towards creating the instruments, which support enabling dance-related initiatives as information services}

By defining a list of important topics for innovation (section 4.1) and principles of working together (section 4.2), interested persons can focus on a concrete initiative aiming at the progression of Dance.

To do it, they need a protected place, outside of their own institutions, where they can actionalise their multi-disciplinary knowledge for actionalising the initiatives and co-creating services. This can be done thanks to Tiers-Lieu for Services (TLS) [22, 20].

Conceptually, TLS is "a social configuration where the encounter between individual entities intentionally engages in the conception of common representations" [22]. In the case of the progression of Dance, the TLS intention is to create an environment helping interested persons to actively contribute to the progression of Dance. TLS is thus focused on:

- launching an action within the TLS theme, according to the expressed initiatives;

- identifying the group of interested persons (TLS participants) and promoting their networking;

- $\quad$ supporting exploration of the situations brought about in Dance by the pandemic.

Each of the above topics (section 4.1) can be a theme for TLS, which would allow to define a group of initiatives and concretise corresponding dance-related information common goods.

TLS sessions can be face-to-face and/or virtual meetings, facilitated by a digital platform dedicated to TLS. TLS takes place under a free license adapted to the constitution of information services and information common goods, under free licenses like the GNU-GPL.

Despite their heterogeneity, TLS participants share the common language, the language of information, so they do not only understand each other, but also share the same informational model, which is essential for the implementation of information services by Service Science specialists.

As the result of such discussions and explorations, the information base corresponding to the suggested initiatives aiming at and being cognitively coherent to the progression of Dance is established. It is now possible to concretise them as information common goods and organise them as informational commons, in order to actionalise them as contributory services.

The main activities of this stage are mostly executed by Service Science specialists and are as follows:

- $\quad$ support TLS;

- formalise dance-related information common goods;

- continue to make sure that created information common goods are contributory; 
- organise them as informational commons;

- define (the myriad of) corresponding services;

- continually explain the sense of the progression in Dance enabled by information services under construction;

- contribute to overcoming possible corresponding issues, while co-constructing information services thanks to digital platforms;

- maintain TLS activities within the framework of the original intention, by ensuring they contribute to the progression of a resilient and sustainable Dance Society;

- co-design and finalise the development of the corresponding (myriad of) service(s) aiming at (some aspects of) the progression of Dance.

It is important to note that services created according to this TLS-assisted co-design guarantee to provide an actionable added value, and are contributory, as they have been developed collaboratively, by respecting the requirements of resilience and sustainability of the progression of Dance Society.

\section{Conclusion}

This research explores transdisciplinary knowledge, skills, motivations, values, deep expectations of all members of Society interested in Dance with an objective to develop services oriented at the progression of Dance. By helping to identify innovative ideas for this progression, it suggests to concretise them as information common goods and organise them as informational commons. This can be done thanks to a protected place oriented co-construction of information services, Tiers-Lieux for Services, which allows fruitful collaboration of all persons interested in Dance and is actionalised thanks to Service Science specialists. This service-oriented approach is not exclusive for the domain of Dance, but can be pertinent for other domains and disciplines. Further research on enrichment and concretisation of this approach in the context of different domains is between its main research perspectives.

The author thanks Prof. Michel Léonard for fruitful discussions and invaluable insight into exploratory aspects of this research. The author is profoundly appreciative to Prof. Marco de Marco and Prof. Thang Le Dihn for their comments on an earlier version of the paper that greatly assisted and stimulated the research through their constructive critical analysis. The author is also very grateful to Sabine Nüssli for ingenious suggestions for improving the paper. The author is deeply indebted to Paula Brough-Heinzman for helpful contributions and unwavering encouragement throughout the duration of this research.

\section{References}

1. M. Léonard, Informational Lights from Service Science for the progression of Society (EDP Sciences, Les Ulis, 2020)

2. H. I. Ansoff, Managing Strategic Surprise by Response to Weak Signals, Calif. Manag. Rev. 18(2), 21-33 (1975)

3. C. Argyris, Actionable knowledge: Design causality in the service of consequential theory, J. Appl. Behav. Sci. 32, 390-406 (1996)

4. J. Spohrer, P.P Maglio, The emergence of service science: Toward systematic service innovations to accelerate co - creation of value, Prod. Oper. Manag. 17(3), 238-246 (2008) 
5. J. Spohrer, S. K. Kwan, Service science, management, engineering, and design (SSMED): An emerging discipline-outline \& references, Int. J. Inf. Syst. Serv. Sect. 1(3), 1-31 (2009)

6. P. P. Maglio, J. Spohrer, Fundamentals of Service Science, J. Acad. Mark. Sci. 36, 18-20 (2008)

7. S. Kinsley, The Economy of Contribution, http://www.samkinsley.com/2012/12/02/economy-of-contribution/ (2012)

8. S. Bonomi, S. Za, M. de Marco, C. Rossignoli, Knowledge Sharing and Value Co-creation: Designing a Service System for Fostering Inter-generational Cooperation, in Proceedings of International Conference on Exploring Service Science, IESS 2015, LNBIP 201, 25-35 (2015)

9. T. Le Dinh, M. C. Vu, A. G. Ayayi, T. S. Nomo, Managing Co-Creation Projects: The Service-Oriented Perspective, J. Mod. Proj. Manag. 5 (3), 100-107 (2018)

10. Yen Han Ballet Productions website, https://www.yenhan-ballet-productions.com/en/about-us/news/item/safer-dancing-with -uvc-technology.html (2021)

11. Toronto's LMNTS Studio initiative, https://www.covidinnovations.com/home/24062020/torontos-lmnts-outdoor-studio-sets -up-50-outdoor-frameless-domes-to-practice-social-distancing-yoga-classes (2021)

12. Dance Live Europe website, https://danceliveeurope.com/ (2021)

13. Special Issue: Innovations in Arts Practice, J. Res. Dance Educ., thttps://think.taylorandfrancis.com/special_issues/dance-health-wellbeing/ (2021)

14. UNESCO website, Culture for Sustainable Development. Resilient Societies, http://www.unesco.org/new/en/culture/themes/culture-and-development/the-future-wewant-the-role-of-culture/disasters/ (2021)

15. Prix de Lausanee website, https://www.prixdelausanne.org/ (2021)

16. European Dancehouse Network, What's Next in Restructuring the Dance Ecosystem, https://www.ednetwork.eu/news/whats-next-in-restructuring-the-dance-ecosystem (2021)

17. J. G. Teixeira, V. Miguéis, M. C. Ferreira, H. Nóvoa, J. F. Cunha, Ten Years Exploring Service Science: Looking Back to Move Forward, in Proceedings of International Conference on Exploring Service Science, IESS 2020, LNBIP 377, 334-346 (2020)

18. E. Ostrom, Governing the Commons: The Evolution of Institutions for Collective Action (Cambridge University Press, 1990)

19. M. Drăgoicea, N. G. Badr, L. M. Manea, Emerging Information Common Goods for the Development of Complex Services in Public Safety, in Proceedings of the 23rd International Conference on System Theory, Control and Computing, ICSTCC 2019, 407-412 (2019)

20. A. Yurchyshyna, Towards Contributory Development by the Means of Services as Common Goods, in Proceedings of International Conference on Exploring Service Science, IESS 2015, LNBIP 201, 12-24 (2015)

21. M. Léonard, A. Yurchyshyna, An Exploratory Approach for Governance of Society for Smarter Life, in Proceedings of International Conference on Advanced Information Systems Engineering, Advanced Information Systems Engineering Workshops, CAiSE 2020 International Workshops (Springer, Cham, 2020) 133-138

22. A. Burret, Étude de la configuration en tiers-lieu : la re-politisation par le service, $P h D$ thesis in Sociology and Anthropology, https://tel.archives-ouvertes.fr/tel-01587759/document (Université des Lumières de Lyon, 2017) 